\title{
Proposal of a Scale with Predictive Factors of Complications Arising from Systemic Arterial Hypertension and Actions for Management of Care
}

\author{
By Elis Martins Ulbrich ${ }^{*}$ \\ Maria de Fátima Mantovani* \\ Ângela Taís Mattei \\ Leila Maria Mansano Sarquis ${ }^{\dagger}$ \\ Juliana Perez Arthur ${ }^{+}$ \\ Taísa Tatiane de Souza Santos
}

\begin{abstract}
The aim of the research is to identify the factors that predict complications of hypertension and to propose a scale of assessment and continuous care. A descriptive, quantitative research held on 18 public health units in the city of Curitiba, Parana, Brazil. In the study 387 adults with hypertension participated. Data were collected through semi-structured interviews and anxiety scales, depression, quality of life, medication adherence and social support. Descriptive and inferential statistics for analysis were used. The statistically significant variables selected for prediction of complications were age, gender, smoking, time of diagnosis, risk classification in the health service, use of medications and depression. In the proposal of the scale after the multivariate analysis and odds ratio, set itself values 0-100, and the severity of risk was defined arbitrarily. There were proposed care management actions according to the correspondence between the number of points and the risk assessed on the scale. Thus, the risk factors were identified and a predictive scale with actions for management of care based on Brazilian guidelines was proposed.
\end{abstract}

Keywords: Adult, Case Management, Chronic Disease, Hypertension, Nursing.

\section{Introduction}

The management of chronic diseases, especially those with a high impact on morbidity and mortality worldwide like Hypertension, requires technologies that assist in the monitoring and treatment of the affected patients, aimed at reducing the development of associated complications.

Hypertension is a clinical multifactorial condition and asymptomatic, primary cause of other cardiovascular diseases, cerebrovascular, renal and visual impairment (Brazilian Society of Hypertension 2010, Coleman 1998).

\footnotetext{
* PhD Student, Federal University of Paraná, Brazil.

* Associated Professor, Federal University of Paraná, Brazil.

* Master Student, Federal University of Paraná, Brazil.

${ }^{\dagger}$ Adjunt Professor, Federal University of Paraná, Brazil.

${ }^{+}$Nursing Student, Federal University of Paraná, Brazil.

N Nursing Student, Federal University of Paraná, Brazil.
} 
Along with Diabetes Mellitus is the leading cause of hospitalization in the Brazilian health system and the socioeconomic impact of these is mainly generated by complications (Ministry of Health of Brazil 2011a, Lessa 2006).

It is believed that the professional performance, especially of nurses in the primary care level, can reduce the rates of hospitalizations and complications caused by hypertension, in order to help reduce the same morbidity and mortality rates (Nonnenmacher et al. 2011, Barreto and Marcon 2013).

One way of acting is to identify the risk factors that can help predict the onset of complications of hypertension, which is a strategy that allows the nurses and other health professionals to develop an individualized treatment plan that meets the single needs of each one, facilitating monitoring and constant control by professionals and patients, and strengthening the bond between them and the health service (Mendes 2012, Malta and Merhy 2010).

Thus, it was questioned: Which factors can predict complications in patients with hypertension? And the objectives were: identifying factors that predict complications of hypertension and proposing a scale of assessment and continuous care.

\section{Method}

This is a descriptive, quantitative research, part of the project funded by the National Council for Scientific and Technological Development $(\mathrm{CNPq})$ in the Universal Official Announcement 2012 by the Araucaria Foundation, Paraná in 2013. The target population was that of individuals with hypertension and the available population was 21,798 hypertensive people registered in 18 health units of a Sanitary District. Establishing the number of hypertensives for the sample was calculated based on the information provided by the City Health Department of Curitiba, Parana, Brazil; through the Annual Operating Plan 2011, in which all system users were recorded.

Sampling was systematic, stratified with replacement and consisted of 387 participants distributed by a risk score (low, medium, high and very high risk). The sample size in each health center was proportional to the number of hypertensive thereof, with a margin of error of 0.05 and $95 \%$ significance level (Figure 1). 
Figure 1. Flow Chart of the Methodology

Selection of 387 participants from

18 health units of primary care

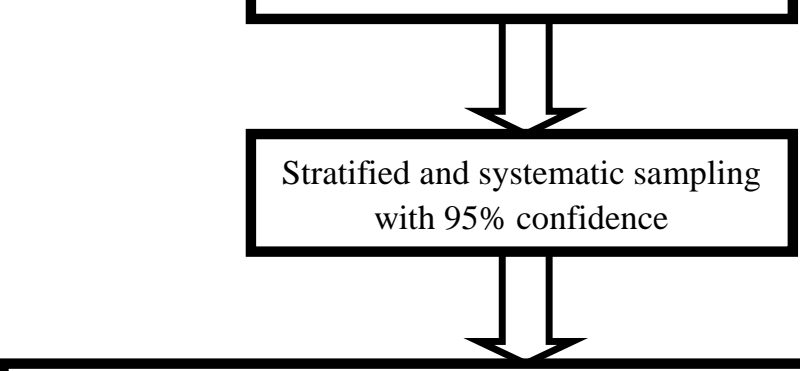

Criteria for inclusion:

- Hypertensive Adults

- Between 18 and 60 years old

- Active in the computerized program of registration and monitoring of patients with Diabetes and Hypertension in public primary health care - Attain the minimum score on the short Examination for Mental State

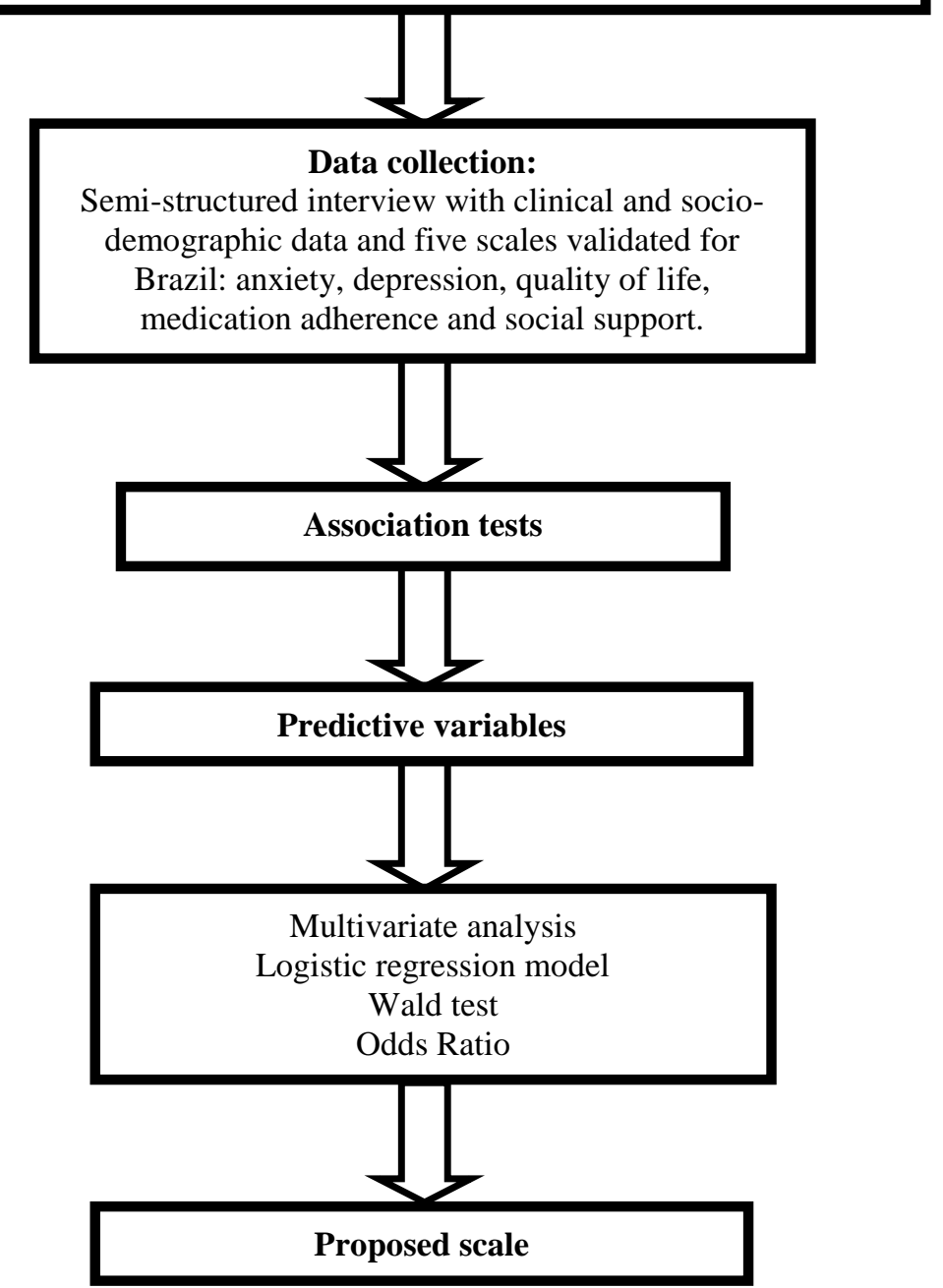


In this study were included patients with diagnosis of hypertension; adults aged 18 to 60; classified as active in the computerized program responsible for registration and monitoring of patients with diabetes and hypertension HIPERDIA system; and reached the minimum score on the Mini Mental State Examination, 13 points for illiterate, 18 for low and intermediate level of education and 26 to high level of education. Low level of education was considered in the case of one to four incomplete years of schooling, intermediate was considered in the case of four to eight incomplete years of schooling and a high level of education corresponded to more than eight years of schooling (Bertolucci et al. 1994). Those who did not obtain the minimum score in this test were excluded.

Data collection was carried by previously trained researchers and undergraduate research students. The collection was performed at the homes of participants from May 2013 to April 2014, in the period from Monday to Friday afternoon, through a semi-structured interview consisting of sociodemographic and economic variables. Self-declared clinics, supplemented by the scale of social support, inventory depression and anxiety Beck, quality of life questionnaire SF36, and medication adherence scale Brief medication questionnaire (BMQ) (Griep et al. 2005, Svarstad et al. 1999). The limitations of this study were the duration of the interviews and that it may have been tiring.

Data were tabulated in Microsoft Excel ${ }^{\circledR}$ and analyzed with the computer program IBM SPSS ${ }^{\circledR}$ Statistics v.20. The results of the quantitative variables were described as average, median, minimum, maximum and standard deviation values and qualitative as frequencies and percentages. To evaluate the association between the variables and the presence of complications, statistical tests were considered: Fisher's exact, Chi-square, Student t-test, Mann-Whitney, and Spearman correlation.

The multivariate analysis was adjusted by the logistic regression model (stepwise backward with a probability 0.05 for input and 0.10 for output of variables). After adjusting the significance of the variables was evaluated considering the Wald test, the odds ratios were calculated (OR) at intervals of 95\% confidence for the model variables.

The evaluation scale of the risk of complications was built considering proportionally OR values of the variables included in the adjusted multivariate model. In all statistical tests, $\mathrm{p}$ values $<0.05$ were considered statistically significant.

The project was approved by the Research Ethics Committee with Humans, of the Sector of Health Sciences of the Federal University of Parana, Opinion 220.068, and by the Municipal Ethics Committee of Health of Curitiba, Parana. 


\section{Results and Discussion}

The socio-demographic and economic characteristics of the 387 participants were: $76.2 \%$ were women, $64.0 \%$ Catholic, $68.7 \%$ married, $82.4 \%$ with up to three children, $65.1 \%$ with less than eight years of schooling, $57.3 \%$ family income up to three minimum wages, $78.6 \%$ in private housing and $62.5 \%$ up to three household members.

The ages ranged from 23-60 years old, with an average of 52.9 years of age (SD 6.7 years). Regarding the profession/occupation $30.5 \%$ performed activities with employment, $29.7 \%$ were housewives, $28.4 \%$ were retired or pensioners of social security, $8.5 \%$ self-employed, $8.0 \%$ domestic and/or day laborers, and $4.9 \%$ received sick pay.

The average salary of the participants was of 947.3 Reals, the reference of the national minimum wage in the period of data collection was of 724,00 Reals. With regard to homeworkers, 52 had no family member performing remunerated work, 262 had up to two family members contributing to the family income, and 73 had more than three family members.

The profiles found in international and national studies about the subject have sociodemographic and economic characteristics similar to those found in this study (Martins et al. 2014, Selem et al. 2013, Oliveira et al. 2013, Uceda et al. 2013, Warren et al. 2012).

The risk for hypertension increases proportionally with age, being $25 \%$ higher in people over 40 years old. The prevalence between men and women is similar in the classification of risk of cardiovascular mortality in European countries (Brazilian Society of Hypertension 2010, Portuguese Society of Hypertension 2014).

Regarding complications, in this study $19.4 \%$ of the participants reported having some corroboration in the study findings held in Fortaleza. It was found that 17.6\% (Romero et al. 2010), and others (Santos and Moreira 2012) aimed to identify risk factors and complications associated in patients with hypertension and diabetes with $17.1 \%$. Complications most often cited by them were heart diseases, acute myocardial infarction, stroke and kidney disease.

The treatment of complications of hypertension needs tertiary health service, resulting often in admissions generating high costs for health systems (Serafim et al. 2013). In Brazil between 2008 and 2012 5,685,827 hospitalizations for circulatory diseases were recorded, and 479,497 of these were due to hypertension (Santos and Vasconcelos 2013).

Thus, the Ministry of Health has adopted various tactics in the core network, to reduce the burden of complications and hospitalizations for chronic diseases in the Brazilian population. However, the great challenge is to translate the technical-scientific knowledge into concrete action within the health system and population level, so that they benefit from the largest possible number of people (Ministry of Health of Brazil 2011b).

The presence of complications of the participants in this study had statistical significance when associated with socio-demographic factors such as age and gender. The first was re-categorized after adjustment of a ROC - 
Receiver Operating Characteristics, which found an area under the curve equal to 0.63 and was statistically significant $(\mathrm{p}<0.001)$. This indicates that the age discriminate between whether or not complications, the indicated cutoff of 55, and related to the male gender.

These findings corroborate the European Guidelines considering males aged 55 or over, a risk factor for cardiovascular mortality (Portuguese Society of Hypertension 2014). Thus, there is a prevalence of men over 55 years old in studies about the complications of hypertension, such as: acute myocardial infarction, stroke, coronary artery disease, kidney disease, among others (Nauta et al. 2011, Paim et al. 2012, Fonseca et al. 2013, Silva et al. 2014).

Complications such as coronary artery disease, acute myocardial infarction, stroke and kidney disease obtained statistical association with hypertension, and this along with diabetes, and $6.2 \%$ had stroke, $4.6 \%$ coronary artery disease, $4.4 \%$ acute myocardial infarction, and $0.9 \%$ kidney disease (Santos and Moreira 2012), a fact that confirms the connection found in this survey among the complications, hypertension and this along with diabetes.

These findings lack highlighted, as the severity of complications, sometimes irreversible or can lead to death. Thus, there are necessary reflections by managers and health professionals in coping strategies against hypertension and diabetes mellitus, particularly the lack of information and not therapeutic compliance (Carvalho Filha et al. 2011).

In a study (Santos and Moreira 2012), which associated the risk aspects with the complications of hypertension and diabetes was perceived as a correlation of family history with coronary artery disease and acute myocardial infarction, unlike this study in which family history did not have statistically significant with the complications of hypertension.

When the association of complications with the questionnaires used in this research was verified, there was statistical significance with SF36 in the physical and mental components, with the BMQ in memory domain and the Beck Depression.

However, in the literature the risk for developing cardiovascular complications related to no control of blood pressure levels is associated with risk factors, such as: obesity, smoking, physical inactivity, abdominal circumference, family history and advanced age (Tavares et al. 2014).

In this research a statistically significant association was found, with the development of complications of the following variables: age, gender, smoking, alcohol consumption, have hypertension and diabetes, time of diagnosis, risk rating, number of medications in use, hospitalizations in the year preceding the interview time daily activities, quality of life in the fields of functional capacity, physical aspects, social, emotional, and mental health, memory for non-medication adherence, and depression.

Selected as predictive indicators to compose the scale of complications for hypertensive patients, are: age, gender, smoking, time of diagnosis, risk rating, number of medications, and depression, as the possibility of assessing these.

In this sense, after identifying predictors for the development of complications associated with hypertension the effect of these on the likelihood 
of occurrence of complications was observed, through a logistic regression model (stepwise backward) including as explanatory variables those that presented $\mathrm{p}<0.05$ in the univariate analysis.

Thus, a scale divided into two parts was proposed, the first with the variables that had statistical significance in the multivariate analysis, and assigned weights based on the values that enabled OR establishment of scores ranging from 0 to 100 . Gravity risk of complication was defined arbitrarily, being lower than $25 \%$, moderate between $25 \%$ and $49.9 \%$, high $50 \%$ to $74.9 \%$, and very high greater than $75 \%$

The second part of the scale is a proposed protocol for the management of care that is being in phase of validation, considering the seriousness of the risk of complication to define care management actions. It is emphasized that one of the limitations to the application of this scale was its conception in hypertensive adult population served in primary care in Brazil (Figure 2).

Figure 2. Proposed Scale

\begin{tabular}{|l|c|}
\hline Variables (p) & Odds Ratio \\
\hline Age $(0.007)$ & $1.90(1.05-3.42)$ \\
\hline Sex $(0.016)$ & $2.14(1.12-4.10)$ \\
\hline Smoking (0.001) & $2.09(1.14-3.83)$ \\
\hline Time of Hypertension diagnosis $(0.001)$ & $2.35(1.29-4.28)$ \\
\hline Risk Classification in Health Unit $(0.001)$ & $3.18(1.53-6.63$ \\
\hline Number of medications used (0.001) & $3.97(2.20-7.16)$ \\
\hline Depression (0.005) Actions for the management of care \\
\hline \multicolumn{2}{|c|}{ Medical and nursing consultations, } \\
\hline \multicolumn{2}{|c|}{ Home visits, } \\
Health education activities, \\
Negotiation of goals with patients, \\
Phone contact for follow up.
\end{tabular}

The actions of care management have been prepared from the guidelines on national, state and municipal manuals. The scale developed meets the research priorities in Brazilian nursing, focusing on a comprehensive view of the health disease and the need to develop promotion techniques, prevention, early diagnosis and treatment of Chronic Diseases with priority for high blood pressure (Oliveira 2014, Ministry of Health of Brazil 2011a).

\section{Conclusions}

Seven predictors for development of complications were identified after multivariate analysis: age, sex, smoking, number of medications, diagnosis time, depression and cardiovascular risk classification. These factors make up the proposed scale that rates the risk for complications and provides support for the management of care. 
The implication of this study is to establish a way to measure and predict the development of complications of hypertension and indicate actions for care management in primary care with a view to prevention

There is a gap in the study that refers to the kind of methodology, which does not provide a relation of cause and effect. Moreover, it has not performed a pre-test scale to evaluate their effect on predicting the development of complications of hypertension.

\section{References}

Barreto MS, Marcon SS (2013) Hospitalização por agravos da hipertensão arterial em pacientes da atenção primária (Hospitalization due to complications of arterial hypertension in primary care patients). Acta Paulista de Enfermagem. 26(4): 31317.

Bertolucci PHF, Brucki AMD, Campacci SR, Julian Y (1994) O Mini-Exame do Estado Mental em uma população geral: impacto da escolaridade (The Mini Mental State Examination in an outpatient population: influence of literacy). Arquivos de Neuro-Psiquiatria 52(1): 1-7.

Ministry of Health of Brazil. Health Surveillance Secretariat. Department of Health Situation Analysis (2011a). Plano de Ações Estratégicas para o enfrentamento das doenças crônicas não transmissíveis no Brasil 2011-2022. (Strategic action plan for coping of chronic non-communicable diseases in Brazil 2011-2022). Brazil: Ministry of Health.

Ministry of Health of Brazil. Secretariat of Science, Technology and Strategic Inputs. Department of Science and Technology (2011b). Prioridades de Pesquisa em Saúde: Ministério da Saúde. (Health Research Priorities: Ministry of Health). Brazil: Ministry of Health.

Brazilian Society of Hypertension (SBH), Brazilian Society of Cardiology (SBC). Brazilian Society of Nephrology (SBN) (2010). VI Diretrizes Brasileiras de Hipertensão (VI Brazilian Guidelines of Hypertension). Arquivos Brasileiros de Cardiologia 95(1).

Carvalho Filha FSS, Nogueira LT, Viana LMM (2011). Hiperdia: adesão e percepção dos usuários acompanhados pela estratégia de saúde da família. (Hiperdia: adhesion and perception of users accompanied by the Family Health Strategy). Revista Rene 12 (esp): 930-936.

Coleman R (1998) Disease burden in sub-Saharan Africa. The Lancet 351(9110): 1208.

Fonseca AM, Silva RL, Nascimento E, Moura JP, Rossi VEC, Souza NR et al. (2013). Infarto agudo do miocárdio: Levantamento de sua ocorrência em homens atendidos de 2008-2012 em um serviço de urgência e emergência de Passos (MG) (Acute myocardial infarction: its occurrence in men reached 2008-2012 in an urgent and emergency service of Passos (MG). Ciência et Praxis 6(12): 29-34.

Griep RH, Chor D, Faerstein E, Werneck GL, Lopes CS (2005) Validade de constructo de escala de apoio social do Medical Outcomes Study adaptada para o português no Estudo Pró-Saúde.(Construct validity of the Medical Outcomes Study's social support scale adapted to Portuguese in the Pró-Saúde Study). Cadernos de Saúde Pública 21(3): 703-714. 
Lessa I (2006) Impacto social da não aderência ao tratamento da hipertensão. (Social impact of non-adherence to the treatment of hypertension). Revista Brasileira de Hipertensão 13(1): 39-46.

Malta DC, Merhy EE (2010) O percurso da linha de cuidado sob a perspectiva das doenças crônicas não transmissíveis (The route of the line under the care of the chronic non-communicable diseases). Interface Comunicação, Saúde e Educação 14(34): 593-605.

Martins AG, Chavaglia SRR, Ohl RIB, Martins IML, Gamba MA (2014) Adesão ao tratamento clínico ambulatorial da hipertensão arterial sistêmica (Compliance with outpatient clinical treatment of hypertension). Acta Paulista de Enfermagem 27(3): 266-272.

Mendes EV (2012) O cuidado as condições crônicas de saúde na atenção primária: o imperativo da consolidação da estratégia de saúde da família (The care of chronic conditions in primary health care: the imperative of consolidation of the family health strategy). Brazil: The Pan American Health Organization.

Nauta ST, Deckers JW, Akkerhuis M, Lenzen M, Simoons ML, Domburg RTV (2011). Changes in clinical profile, treatment, and mortality in patients hospitalized for acute myocardial infarction between 1985 and 2008. Plos One 6(11):1-7.

Nonnenmacher CL, Weiller TH, Oliveira SG (2011) Acesso à saúde: limites vivenciados por usuários do sus na obtenção de um direito (Access to health care: limits experienced by users of SUS in obtaining the right). Ciência, Cuidado e Saúde 10(2): 248-255.

Oliveira DC (2014) Prioridades de pesquisa em saúde e as áreas de conhecimento em enfermagem (Health research priorities and areas of knowledge in nursing). Revista de enfermagem UERJ 22(5): 567-568.

Oliveira RG, Frota NM, Martins ABT, Silva CJA, Santos ZMSA (2013) Adesão do usuário hipertenso ao tratamento e a interface com o relacionamento familiar (Accession of user interface and treatment hypertensive relationship with the family). Revista de enfermagem da UFPI 2(4): 42-49.

Paim CP, Azzolin KO, Moraes MAP (2012) Dor torácica no infarto agudo do miocárdio entre pacientes diabéticos e não diabéticos (Chest pain in acute myocardial infarction among diabetic and non-diabetic patients). Revista Brasileira de Enfermagem 65(1): 77-82.

Portuguese Society of Hypertension (2014) Tradução portuguesa das Guidelines de 2013 da ESH/ESC para o Tratamento da Hipertensão Arterial (Portuguese translation of the Guidelines of the $2013 \mathrm{ESH} / \mathrm{ESC}$ for the treatment of hypertension). Portuguese Journal of Hypertension and Cardiovascular Risk. $39(1)$.

Romero AD, Silva MJ, Silva ARV, Freitas RWJF, Damasceno MMC (2010) Caractervsticas de uma populan $\gamma$ o de idosos hipertensos atendida numa unidade de saïde da famvlia (Characteristics of a population of elderly hypertensive patients attended in a family health unit). Revista Rene 11(2): 72-78.

Santos JC, Moreira TMM (2012) Fatores de risco e complicações em hipertensos/diabéticos de uma regional sanitária do nordeste brasileiro (Risk factors and complications in hypertensive/diabetic patients of a regional health of the Brazilian Northeast). Revista da Escola de Enfermagem da USP. 46(5): 11251132 .

Santos SS, Vasconcelos DFSA (2013) Hospitalizações por hipertensão arterial essencial em caráter de urgência no Brasil, 2008-2012 (Hospitalizations for 
hypertension: essence on the basis of urgency in Brazil, 2008-2012). Revista de Ciências Médicas e Biológicas 12(esp): 465-471.

Serafim WP, Rodrigues FSM, Barbané AS, Arçari DP, Fornari JV, Rodrigues AME et al. (2013) Hypertension as the main reason for the admission of a medical clinic in a public hospital in the city of São Paulo: brief observational study. Saúde em Foco 7(1): 55-59.

Selem SSC, Castro MA, César CLG, Marchioni, DML, Fisberg RM (2013) Validade da hipertensão autorreferida associa-se inversamente com escolaridade em brasileiros (Validity of self-referred to hypertension associated inversely with education in Brazilians). Arquivo Brasileiro de Cardioogia 100(1): 52-59.

Silva FS, Silva SYB, Pinheiro MGC, Pinheiro MSF, França RC, Simpson CA (2014) Cuidados paliativos para dor originada da doença mineral óssea da insuficiência renal crônica (Palliative care for pain arising from bone mineral disease of chronic renal failure). Revista Cuidado é Fundamental 6(2): 767-775.

Svarstad BL, Chewning BA, Sleath BL, Claesson C (1999) The Brief Medication Questionnaire: a tool for screening patient adherence and barriers to adherence. Patient Education and Counseling 37(2): 113-124.

Tavares RS, Silva DMGV, Sasso GTMD, Padilha MICS, Santos CRM (2014) Fatores de risco cardiovascular: estudo com pessoas hipertensas de um bairro popular na região da Amazônia (Cardiovascular risk factors: study of hypertensive people from a popular neighborhood in the Amazon region). Ciência, Cuidado e Saúde 13(1): 4-11.

Uceda IM, Fernández JS, López RE, García-Vera MP (2013) Perfil emocional y cognitivo de la hipertensión arterial esencial mantenida frente a la normotensión (Emotional and cognitive profile of hypertension held opposite the normotension) Clinica y Salud 24(2): 67-76.

Warren TY, Wilcox S, Dowda M, Baruth M (2012) Independent association of Waist Circunference with hypertension and diabetes in African American women, South Carolina, 2007-2009. Preventing Chronic Disease 9(E105): 1-9. 